Article

\title{
Effects of di-(2-ethylhexyl) phthalate on Transcriptional Expression of Cellular Protection-Related HSP60 and HSP67B2 Genes in the Mud Crab Macrophthalmus japonicus
}

\author{
Kiyun Park ${ }^{1}$, Won-Seok Kim ${ }^{2}$ and Ihn-Sil Kwak ${ }^{1,2, *}$ \\ 1 Fisheries Science Institute, Chonnam National University, Yeosu 59626, Korea; ecoblue@hotmail.com \\ 2 Faculty of Marine Technology, Chonnam National University, Yeosu 59626, Korea; csktjr123@gmail.com \\ * Correspondence: iskwak@chonnam.ac.kr; Tel.: +82-61-6597148; Fax: +82-61-6597149
}

Received: 10 March 2020; Accepted: 14 April 2020; Published: 16 April 2020

\begin{abstract}
Di-2-ethylhexyl phthalate (DEHP) has attracted attention as an emerging dominant phthalate contaminant in marine sediments. Macrophthalmus japonicus, an intertidal mud crab, is capable of tolerating variations in water temperature and sudden exposure to toxic substances. To evaluate the potential effects of DEHP toxicity on cellular protection, we characterized the partial open reading frames of the stress-related heat shock protein 60 (HSP60) and small heat shock protein 67B2 (HSP67B2) genes of $M$. japonicus and further investigated the molecular effects on their expression levels after exposure to DEHP. Putative HSP60 and small HSP67B2 proteins had conserved HSP-family protein sequences with different $C$-terminus motifs. Phylogenetic analysis indicated that $M$. japonicus HSP60 (Mj-HSP60) and M. Japonicus HSP67B2 (Mj-HSP67B2) clustered closely with Eriocheir sinensis HSP60 and Penaeus vannamei HSP67B2, respectively. The tissue distribution of Heat shock proteins (HSPs) was the highest in the gonad for Mj-HSP60 and in the hepatopancreas for Mj-HSP67B2. The expression of Mj-HSP60 Messenger Ribonucleic Acid (mRNA) increased significantly at day 1 after exposure to all doses of DEHP, and then decreased in a dose-dependent and exposure time-dependent manner in the gills and hepatopancreas. Mj-HSP67B2 transcripts were significantly upregulated in both tissues at all doses of DEHP and at all exposure times. These results suggest that cellular immune protection could be disrupted by DEHP toxicity through transcriptional changes to HSPs in crustaceans. Small and large HSPs might be differentially involved in responses against environmental stressors and in detoxification in $M$. japonicus crabs.
\end{abstract}

Keywords: di(2-ethylhexyl) phthalate (DEHP); crustacean; heat shock proteins (HSPs); gene expression; environmental risk assessment

\section{Introduction}

Artificial chemical additives have come to the fore as one of the main environmental pollution triggers. Plasticizers, which assign flexibility and durability to plastic, have been heavily utilized, owing to the widespread application of plastic products. As the most common plasticizer, di-2-ethylhexyl phthalate (DEHP) has contributed to the manufacture of flexible products from solid plastics such as polyvinyl chloride [1]. Owing to its widespread use, DEHP is ubiquitously released into the aquatic environment [2,3]. A recent study showed that the main source of DEHP is emissions from household sewage and sludge disposal activities [2]. DEHP is detected at high levels in all sediment samples taken from coastal bays, indicating ubiquitous contamination of the marine environment [3]. DEHP concentrations were found to range from 3020 to $3970 \mathrm{ng} / \mathrm{g}$ in sediments from the Kuwait Coast, Pearl River Delta in China, and Kaohsiung Harbor in Taiwan [4-6]. In addition, in the northwestern 
Mediterranean Sea, the range of DEHP concentrations was $42-802 \mathrm{ng} \mathrm{L}^{-1}$ and $130-924 \mathrm{ng} \mathrm{L}^{-1}$ in the surface seawater (depth $0.5 \mathrm{~m}$ ) and bottom seawater (depth $30 \mathrm{~m}$ ), respectively [7]. DEHP concentrations were found to range from 62 to $4352 \mathrm{ng} \mathrm{L}^{-1}$ from the bottom to the surface seawater of the Bohai Sea and the Yellow Sea, China [8]. DEHP, an endocrine-disrupting chemical (EDC), exhibits a perturbing effect on steroidogenesis activities $[9,10]$.

Macrophthalmus japonicus is one of the main benthic species ubiquitously detected in tidal flats and shows high distribution rates in estuarine regions of Korea and Japan [11,12]. As a main member of the tidal flat food chain, this species contributes to the maintenance of biodiversity in estuarine ecosystems. Because of their dominant distribution, crabs might be a good candidate organism to sense changes in the condition of the surrounding environment, as well as changes involving food reserves, as they have abundant nutrients and are of high economic value in commercial fisheries. However, crab habitats are easily exposed to great hazards, such as plastic waste pollutants and chemicals that are transported into mud flats through rivers or from the ocean. The effects of various stress conditions, such as salinity and heavy metal and biocide contaminants, have been reported following expression analysis of immune-related or stress-related genes in crabs [11,13-16]. A recent study showed the relationships between EDCs and gene expression alterations involving crab innate immune systems [17], but there have been no studies of the relationship between stress-related gene expression and EDC exposure. Despite its biological importance as a nutritional resource, few studies have been conducted on the M. japonicus genomic DNA sequence.

Heat shock proteins (HSPs) are ubiquitous proteins secreted in cells after exposure to stressful conditions and are classified into six major groups (HSP27, HSP60, HSP70, HSP90, and large HSPs) based on their molecular weights $[18,19]$. HSPs function as molecular chaperones to prevent the formation of denatured proteins during high temperature stress and exhibit upregulation in their expression patterns under such stress conditions $[18,20]$. In addition, these stress proteins play an important role in the maintenance of normal polypeptide structures and in the promotion of correct refolding of cellular proteins in response to various external stimuli, such as anoxia, heavy metals, or chemicals, which cause protein denaturation [20-22]. HSPs assist in protecting cellular homeostasis from such stress. HSP60 is well known as a pro-apoptotic molecule, which induces apoptosis and acts as a chaperone for proteins transcribed from mitochondrial DNA [23-25]. HSP60 is a highly immunogenic protein, which is implicated in a variety of autoimmune diseases [26,27]. The upregulation of HSP60 indicates its involvement in crucial functions mediating immune responses in the Chinese mitten crab, Eriocheir sinensis, after crustacean pathogen infection [27]. HSP67B2 was characterized as a Relish-regulated gene in the innate immunity of the Chinese shrimp (Fenneropenaeus chinensis) [28]. However, there is limited information about the molecular characterization and expression responses involving the crustacean HSP67B2.

In the present study, we identify two stress-related genes, Mj-HSP60 and Mj-HSP67B2, in $M$. japonicus crabs to evaluate the toxic effects of DEHP on cellular immune protection in crustaceans. We investigate the genomic structure, phylogenetic relationships with other homologous HSPs, and transcriptional responses of HSPs under DEHP stress. We seek to provide molecular information regarding the influence of EDCs on stress-related gene expression in M. japonicus.

\section{Materials and Methods}

\subsection{Ethical Statement}

All experiments involving M. japonicus crabs in this study were carried out in accordance with the guidelines and regulations approved by the Institutional Animal Care and Use Committee of Chonnam National University. 


\subsection{Preparation of M. japonicus Individuals}

Crabs used in this study were collected from the Yeosu marine products market in Korea. All individuals involved were $3 \pm 0.5 \mathrm{~cm}$ in shell height, $3.5 \pm 0.8 \mathrm{~cm}$ in shell width, and $7.5 \pm 3.5 \mathrm{~g}$ in body weight. We prepared glass tanks $(45.7 \times 35.6 \times 30.5 \mathrm{~cm})$ filled with seawater at $18{ }^{\circ} \mathrm{C}$, with $25 \%$ salinity and a photoperiod of $12 \mathrm{~h}$. Crabs were stabilized in glass tanks for 1 day prior to exposure to DEHP solutions. After 1 day, healthy, undamaged crabs were selected for DEHP exposure experiments (below).

\subsection{DEHP Exposure Experiments}

DEHP solutions were made from a solid compound (99\%, Junsei Chemical Co. Ltd., Tokyo, Japan). For preparation of a $10 \mathrm{mg} \mathrm{L}^{-1}$ stock solution of DEHP, we dissolved DEHP in $99 \%$ acetone at room temperature. This stock solution was diluted with seawater for DEHP solutions with concentrations of 1,10 , and $30 \mu \mathrm{g} \mathrm{L}^{-1}$. A concentration of $<0.5 \%$ acetone was used as a solvent control. For the DEHP exposure experiments, a total of 40 crabs were randomly divided into four experimental groups $(1,10$, and $30 \mu \mathrm{g} \mathrm{L}^{-1}$ DEHP solutions and solvent control). Ten crabs were placed in each glass tank and exposed to one of the three doses of DEHP over days 1, 4, and 7, respectively. Three individuals were selected for tissue extraction at each time interval from the DEHP treatment and control groups. Food was not provided for the crabs, but seawater with equivalent concentrations of DEHP was added every day during the experiments. The experiments were conducted in triplicate with independent samples.

\subsection{Total RNA Extraction and $c D N A$ Synthesis}

Crab gill and hepatopancreatic tissues were acquired from the exposure and control groups. Total RNA was extracted using TRIzol reagent (Life Technologies, Rockville, MD, USA) with Recombinant DNase I (Takara, Otsu, Japan) according to the manufacturers' protocols. The concentration of each RNA sample was measured using a Nano-Drop 1000 (Thermo Fisher Scientific, Waltham, MA, USA). RNA integrity was checked by $1 \%$ agarose gel electrophoresis. Single-stranded Complementary Deoxyribonucleic Acid (cDNA) synthesis was carried out with $1000 \mathrm{ng}$ of total RNA using an oligo dT primer $(50 \mu \mathrm{M})$ for reverse transcription in $20 \mu \mathrm{L}$ reactions (PrimeScript ${ }^{\mathrm{TM}} 1$ st strand cDNA synthesis kit, Takara) according to the manufacturer's protocol.

\subsection{Gene Expression Analysis Using Quantitative Reverse-Transcription PCR (RT-PCR) Amplification}

To confirm the expression patterns of Mj-HSP60 and Mj-HSP67B2 in various tissues of M. japonicus, and in the control and DEHP-exposed samples, quantitative RT-PCR was carried out on an ExicyclerTM96 instrument (Bioneer, Daejeon, Korea). Each reaction was conducted in a final volume of $20 \mu \mathrm{L}$ containing $10 \mu \mathrm{L}$ of Accuprep $\AA 2 \times$ Greenstar qPCR Master Mix (Bioneer, Daejeon, Korea), $6 \mu \mathrm{L}$ of DEPC-treated water, $0.5 \mu \mathrm{L}$ each of sense primer and antisense primer $(10 \mathrm{pM})$, and $3 \mu \mathrm{L}$ of 30 -fold diluted cDNA sample as a template. Quantitative RT-PCR of two genes was carried out for 40 cycles of $95{ }^{\circ} \mathrm{C}$ for $15 \mathrm{~s}$ and $60{ }^{\circ} \mathrm{C}$ for $45 \mathrm{~s}$ using the following primer pairs: Mj-HSP60 forward 5'-CCCTGAAGGATGAGCTTGAG-3'; Mj-HSP60 reverse $5^{\prime}$-GCTGGGATGATGGA CTGAAT-3'; Mj-HSP67B2 forward 5'-GAGCCGCGGTAGATTCTAT G-3'; Mj-HSP67B2 reverse 5'-CTGGACAAGGAGGGTTTCAA-3'; Glyceraldehyde-3-Phosphate Dehydrogenase (GAPDH) forward 5'-TGCTGATGCACCCATGTTT G-3'; and GAPDH reverse 5'-AGGCCCTGGACAATCTCAA AG-3'. Melting curves were determined by increasing the temperature from $68^{\circ} \mathrm{C}$ to $94^{\circ} \mathrm{C}$. All samples were amplified in triplicate to ensure reproducibility. The relative expression level of each transcript was determined using M. japonicus GAPDH as an internal reference gene and employing the $2^{-\Delta \Delta C t}$ method [29]. 


\subsection{M. japonicus Hsp Identification and Bioinformatics Analysis}

Two HSP genes (Mj-HSP60 and Mj-HSP67B2) were identified by screening a previously generated 454 GS-FLX transcriptome database. Sequences were analyzed based on nucleotide and protein databases using the BLASTN and BLASTX programs (National Center for Biotechnology Information, U.S. National Library of Medicine, Bethesda, MD, USA), respectively [30]. Two domains, the chaperonin-like super family of $M j-H S P 60$ and Rhodonase (RHOD) superfamily of $M j-H S P 67 B 2$, were identified by PROSITE profile analysis [31]. A phylogenetic tree for the two HSPs was generated by the neighbor joining method using Molecular Evolutionary Genetic Analysis (MEGA X, Pennsylvania State University, State College, PA, USA) [32] with 1000 bootstrap replications.

\subsection{Statistical Analysis}

The Statistical Package for the Social Sciences (SPSS) 12.0 KO (SPSS Inc., Chicago, IL, USA) was used for statistical analysis in this study. Data are presented as the mean \pm standard deviation. Two-way analysis of variance was conducted to identify the statistical effects of the exposure period and each DEHP dose on Mj-HSP60 and Mj-HSP67B2 mRNA expression. Significant differences were presented as ${ }^{*} P<0.05$ and ${ }^{*} P<0.01$.

\section{Results}

\subsection{Characterization of Mj-HSP60 and Mj-HSP67B2 in M. japonicus}

We identified two HSP genes (Mj-HSP60 and Mj-HSP67B2) in our 454 GS-FLX transcriptome analysis [33] that were composed of 1360 nucleotides (nt) and $511 \mathrm{nt}$, which comprised open reading frames encoding 330 and 149 amino acids, respectively (Figures 1A and 2A). Mj-HSP60 encoded a mature protein of 330 amino acids, $75 \mathrm{bp}$ of $5^{\prime}$ untranslated region (UTR) and $57 \mathrm{bp}$ of $3^{\prime}$ UTR, with a putative methionine initiation codon (ATG) beginning at $58 \mathrm{nt}$ and a stop codon ending at $1224 \mathrm{nt}$. The SignalP Server (ExPASy) [34] predicted that the first 28 amino acids in the N-terminal region of the polypeptide chain would form a signal peptide sequence. We found that $M j-H S P 60$ included a chaperonin-like super family main domain, whereas a RHOD superfamily motif was detected in Mj-HSP67B2 (Figure 2A). The predicted molecular mass of the deduced amino acid sequence was $61 \mathrm{kDa}$, with an estimated isoelectric point (pI) of 5.74. Mj-HSP60 was identified by a BLAST search of the National Center for Biotechnology Information (NCBI) non-redundant (nr) database. To understand the evolutionary position of the Mj-HSP60, we undertook phylogenetic analysis using another 11 species of crustaceans. As shown in Figure 1B, the phylogenetic tree consisted of two clades involving 12 crustacean species. The Mj-HSP60 formed one main clade with other crabs (Eriocheir sinensis, Scylla paramamosain, and Portunus trituberculatus) and crayfish (Cherax cainii, Cherax quadricarinatus, and Cherax destructor). The other clade was composed of shrimp species (Macrobrachium nipponense, Macrobrachium rosenbergii, Penaeus japonicus, Penaeus monodon, and Penaeus vannamei). For clear annotation of $M j-H S P 67 B 2$, we examined the RHOD superfamily domain sequence (98 amino acids) using BLASTN searches of the nr database to detect sequences of other species with high similarity. We carried out pairwise alignment of Mj-HSP67B2 using EMBOSS alignment (EMBL-EBI, Cambridgeshire, UK) [35] with sequences identified in BLAST searches. The results showed $35.9-72.8 \%$ sequence identity, $54.4-81.6 \%$ similarity, and $4.9-10.5 \%$ gap percentage when compared with HSP67B2 from other species (Table 1). The Mj-HSP67B2 sequence revealed considerable identity $(72.8 \%)$, similarity $(81.6 \%)$, and gap percentage $(4.9 \%)$ with Penaeus vannamei HSP67B2. In addition, phylogenetic analysis of the Mj-HSP67B2 was carried out using data from various arthropod species, owing to deficient genomic information regarding the HSP67B2 in crustaceans (Figure 2B). The results showed that the two main clades were divided into Crustacea and Insecta, including mosquito and fly species. The Mj-HSP67B2 showed the closest phylogenetic relationship to Penaeus vannamei HSP67B2. Given these results from analysis of phylogenetic and pairwise sequence alignment comparisons, our transcript sequence from the transcriptome database was identified as Mj-HSP67B2. 
(A)

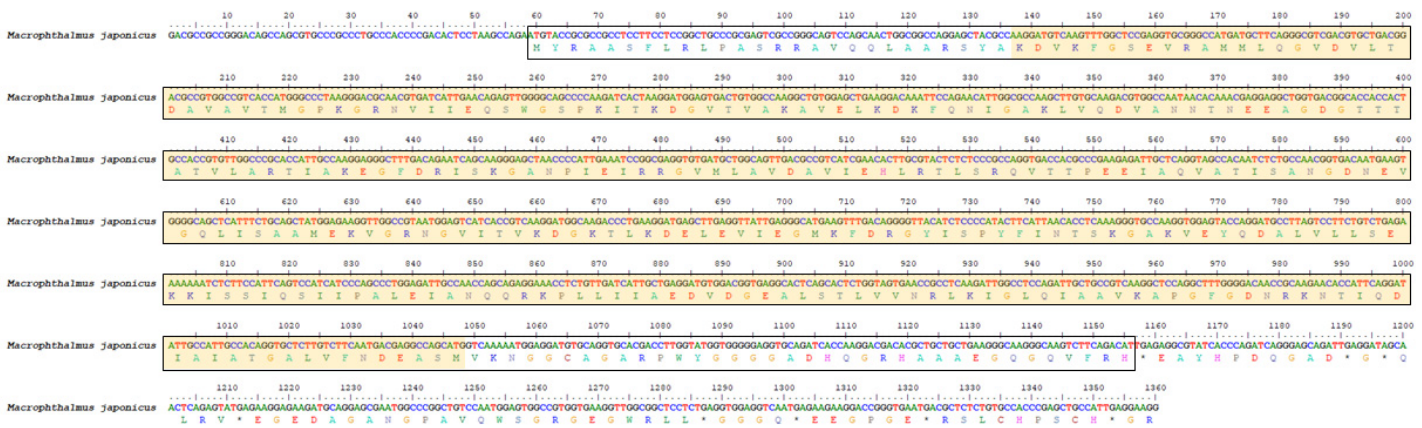

(B)
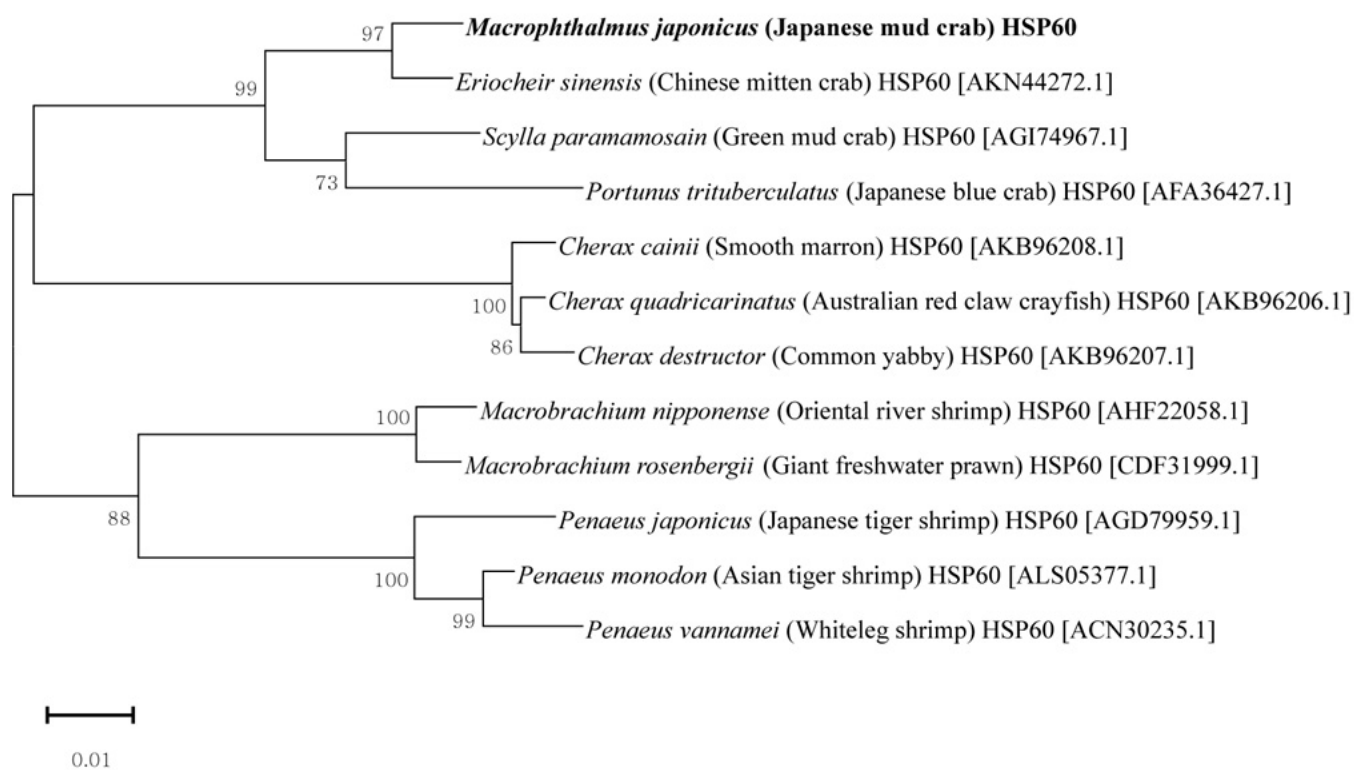

Figure 1. Genomic information of Macrophthalmus japonicus HSP60 sequences identified in this study. (A) Mj-HSP60 structure was represented using the BioEdit program (North Carolina State University, Raleigh, NC, USA). The open reading frame (ORF) of Mj-HSP60 was predicted using the ExPASy tool and is shown as a black box. The yellow box indicates the chaperonin-like super family domain. (B) Phylogenetic analysis of Mj-HSP60 with known HSP60 sequences from 11 Crustacean species. The phylogenetic tree is based on amino acid sequences translated from Mj-HSP60 ORF by the neighbor joining method (bootstrap value 1000) using MEGA X software. The numbers at the nodes represent the bootstrap majority consensus values for 1000 replicates. GenBank accession numbers are shown with scientific and common names of each species.

\subsection{Expression Analysis of Mj-HSP60 and Mj-HSP67B2 in Various Tissues of M. japonicus}

To better understand the expression patterns of Mj-HSP60 and Mj-HSP67B2, quantitative RT-PCR was carried out for six tissue sources (gill, hepatopancreas, muscle, gonad, heart, and stomach) of M. japonicus. The highest level of Mj-HSP60 expression was found in the gonad, while Mj-HSP67B2 was predominantly expressed in the hepatopancreas (Figure 3). In the gonad, Mj-HSP60 was expressed 3.7-fold higher than Mj-HSP67B2. In contrast, Mj-HSP67B2 exhibited a higher expression level than Mj-HSP60 in the gills (1.7-fold) and hepatopancreas (3.1-fold). Relatively low levels of Mj-HSP60 and Mj-HSP67B2 expression were observed in the muscle, heart, and stomach tissues. 
(A)

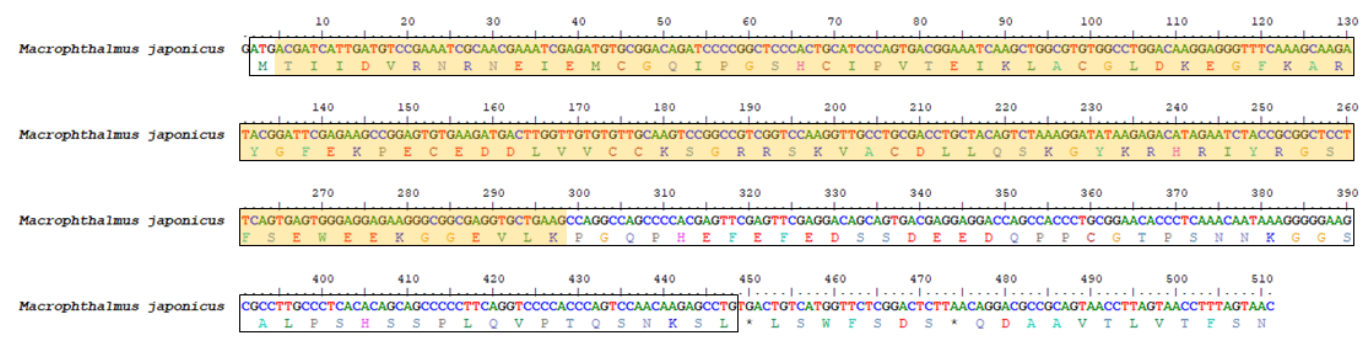

(B)
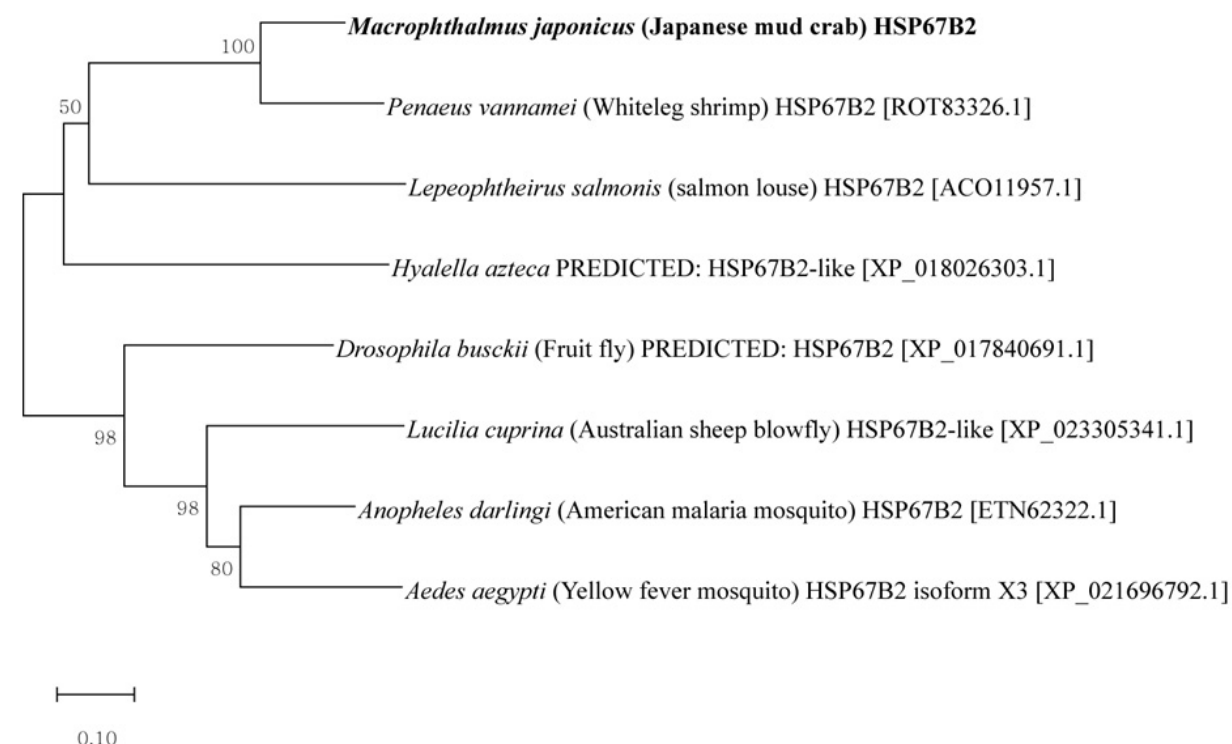

Figure 2. Sequence information for Macrophthalmus japonicus HSP67B2 identified in this study. (A) An open reading frame (ORF) of Mj-HSP67B2 was predicted using the ExPASy tool and is represented by a black box. The yellow box indicates a RHOD superfamily domain. (B) Phylogenetic analysis of Mj-HSP67B2 with known HSP67B2 sequences from seven Arthropoda species. The phylogenetic tree is based on amino acid sequences translated from $M j-H S P 67 B 2$ ORF by the neighbor joining method (bootstrap value 1000) using MEGA X software. The numbers at the nodes represents the bootstrap majority consensus values for 1000 replicates. GenBank accession numbers are shown with the scientific and common names of each species.

Table 1. Percentage identity, similarity, and gaps involving Macrophthalmus japonicus HSP67B2 and HSP67B2 homologs from other species at the amino acid level

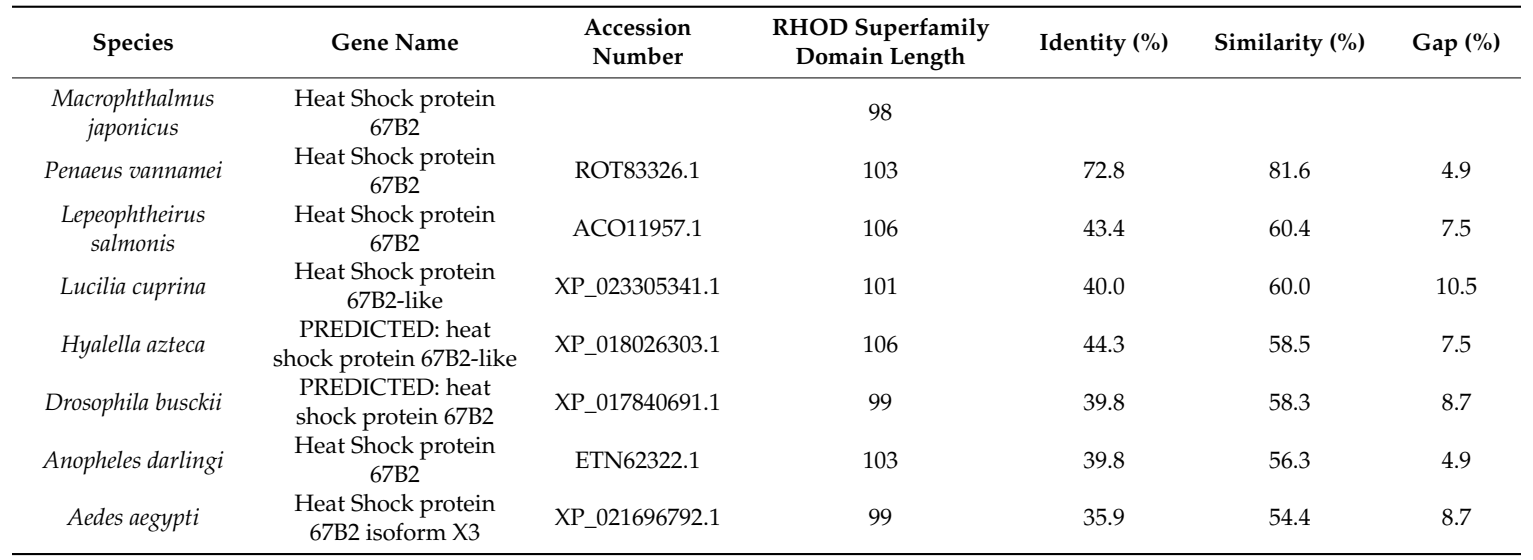

Pairwise identity percentage was calculated using the EMBOSS alignment program. 


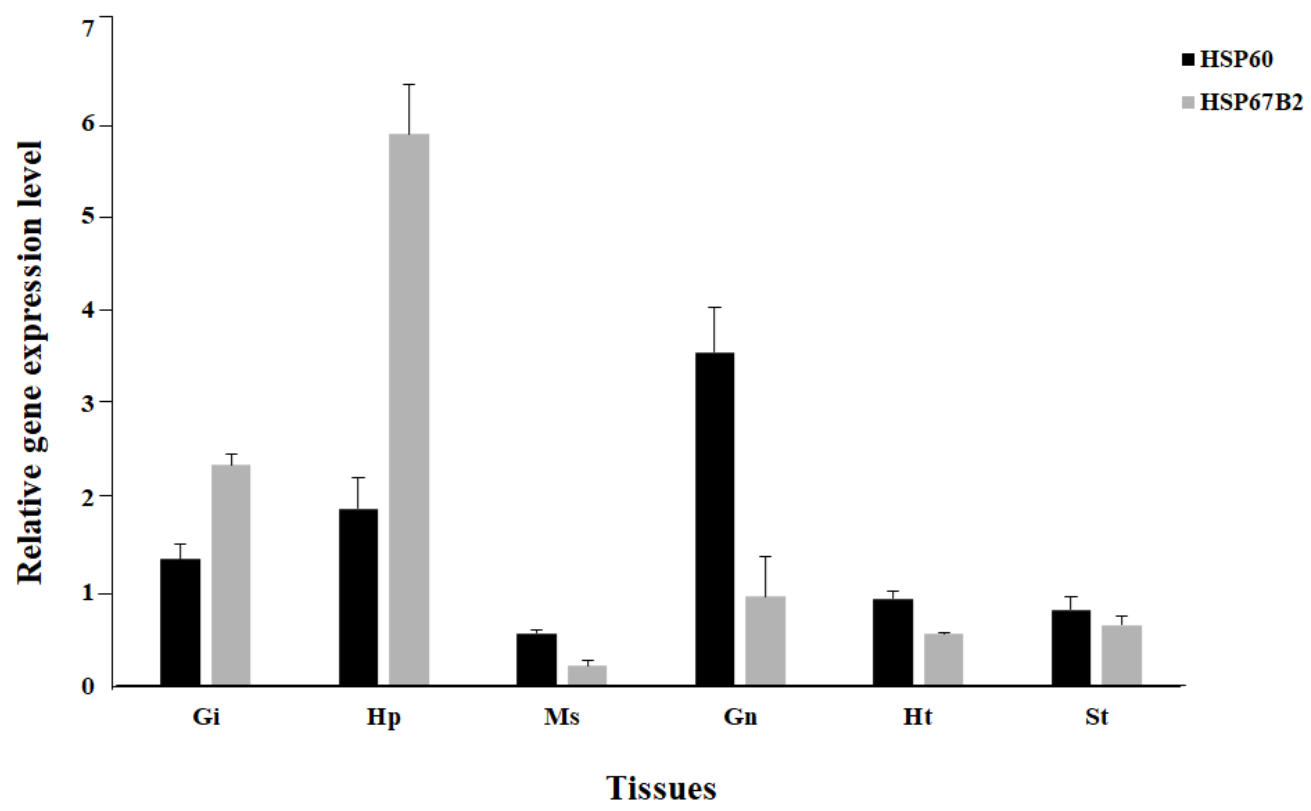

Figure 3. Relative mRNA expression levels of HSP60 and HSP67B2 in various Macrophthalmus japonicus tissues. Six tissues were used in this experiment. Quantitative reverse-transcription (RT)-PCR was conducted in triplicate. Bars indicate the standard deviation of the mean. mRNA expression was normalized against GAPDH. Abbreviations: Gill (Gi), Hepatopancreas (Hp), Muscle (Ms), Gonad (Gn), Heart (Ht), and Stomach (St).

\subsection{M. japonicus Mj-HSP60 Expression Changes after DEHP Exposure}

To confirm the effects of DEHP exposure on Mj-HSP60 expression, we conducted quantitative RT-PCR analysis using mRNA acquired from the gill and hepatopancreas samples after exposure to DEHP for 1, 4, and 7 days. Mj-HSP60 was expressed approximately 8.2-fold higher after exposure to $1 \mu \mathrm{g} \mathrm{L}{ }^{-1}$ DEHP $(P<0.01)$, 3.2-fold higher for $10 \mu \mathrm{g} \mathrm{L}^{-1}(P<0.05)$, and 9.4-fold higher for $30 \mu \mathrm{g} \mathrm{L}^{-1}$ $(P<0.01)$ in the gill tissue on day 1 (Figure $4 \mathrm{~A})$. With the passage of time, expression levels gradually decreased in all DEHP concentration groups. By day 4, for the 10 and $30 \mu \mathrm{g} \mathrm{L}^{-1}$ treatment groups, expression levels were restored to control levels. By day 7, Mj-HSP60 expression levels were lower than those of the control. In particular, sharp decreases in expression levels were found in $10 \mu \mathrm{g} \mathrm{L}^{-1}$ (0.3-fold) and $30 \mu \mathrm{g} \mathrm{L}{ }^{-1}(0.21$-fold $)(P<0.05)$ groups. In the hepatopancreatic tissue, expression levels of Mj-HSP60 exhibited an overall increased pattern compared to the expression levels in the controls on day 1 (Figure 4B). Expression levels significantly increased by 2.4 -fold for $1 \mu \mathrm{g} \mathrm{L}^{-1}$, 2.6-fold for $10 \mu \mathrm{g} \mathrm{L}^{-1}$, and 2.9-fold for $30 \mu \mathrm{g} \mathrm{L}^{-1} \operatorname{DEHP}(P<0.05)$. By days 4 and $7, M j$-HSP60 expression levels returned to control levels for the $1 \mu \mathrm{g} \mathrm{L}{ }^{-1}$ group. In the $10 \mu \mathrm{g} \mathrm{L}{ }^{-1}$ DEHP group, $M j-H S P 60$ expression decreased to $<0.5$-fold on day 4 , and then recovered slightly toward that of control levels by day 7 .

\subsection{Variation in Expression of Mj-HSP67B2 after DEHP Exposure in M. japonicus}

Expression of Mj-HSP67B2 consistently increased in the gill and hepatopancreatic tissues for 4 days after DEHP exposure at all concentrations (Figure 5). After a peak in expression at day 4, $M j-H S P 67 B 2$ levels somewhat decreased. These Mj-HSP67B2 expression patterns were found in the two tissues, regardless of DEHP exposure concentration. Although expression levels of $M j-H S P 67 B 2$ decreased after day 4, the expression was still maintained in the gill tissue at higher levels than those of the controls for all concentration groups, except on day 7 (0.86-fold) for the $1 \mu \mathrm{g} \mathrm{L}^{-1}$ group (Figure 5A). Similar changes in Mj-HSP67B2 expression levels were noted in the hepatopancreas tissue. $M j-H S P 67 B 2$ was strongly overexpressed for 4 days in response to exposure to all concentrations of DEHP $(P<0.05)$, and its expression levels displayed dose-dependent and time-dependent increases for 
4 days (Fig. 5B). The highest expression levels were noted on day 4 in each DEHP concentration group (3.9-fold for $1 \mu \mathrm{g} \mathrm{L}^{-1}(P<0.05)$, 5.48-fold for $10 \mu \mathrm{g} \mathrm{L}^{-1}(P<0.01)$, and 5.88-fold for $30 \mu \mathrm{g} \mathrm{L}^{-1}(P<0.01)$.

(A)

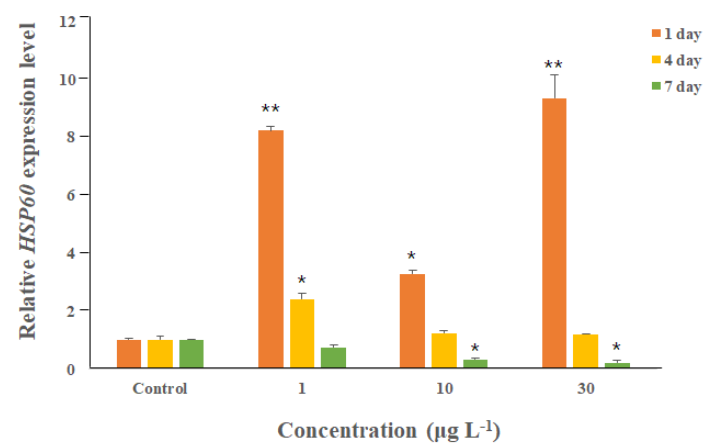

(B)

HEPATOPANCREAS

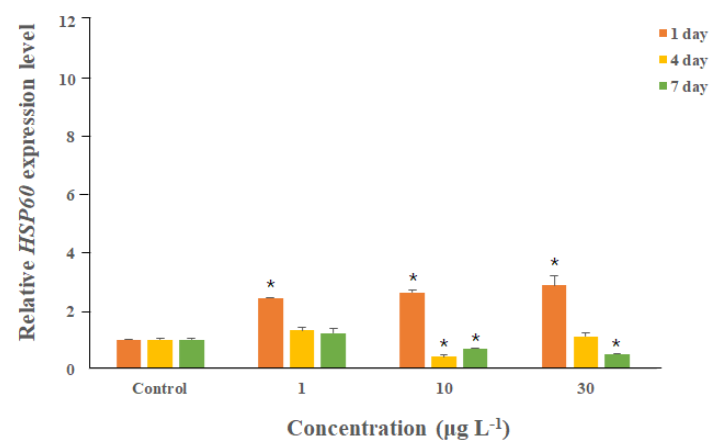

Figure 4. Expression analysis of HSP60 in the (A) gill and (B) hepatopancreas of Macrophthalmus japonicus exposed to 1, 10, and $30 \mu \mathrm{g} \mathrm{L} \mathrm{L}^{-1} \mathrm{DEHP}$ after 1, 4, and 7 days. Values were normalized against $G A P D H$. Bars indicate the standard deviation of the mean. Statistically significant differences are represented by asterisks as ${ }^{*} P<0.05$ and ${ }^{* *} P<0.01$, compared to controls (control ratio value $=1$ ).

(A)

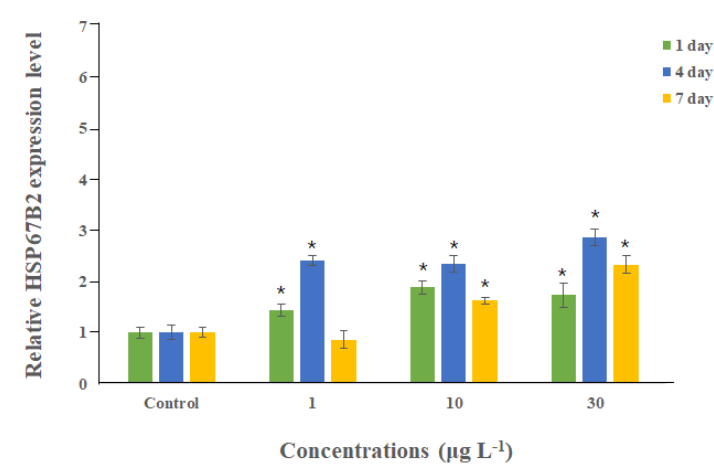

(B)

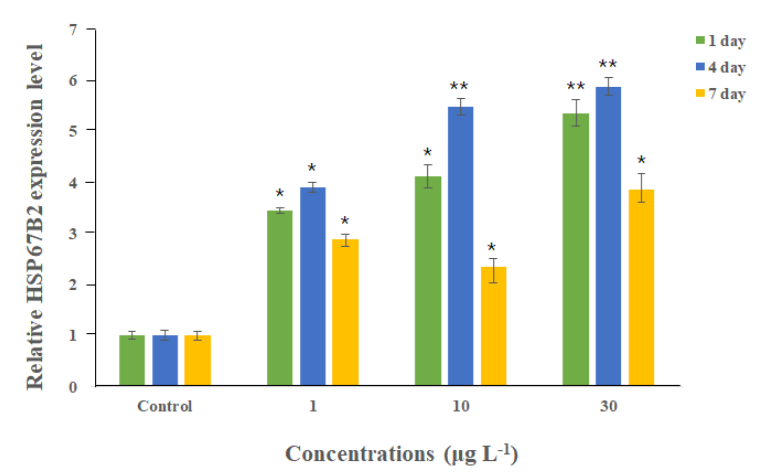

Figure 5. Expression analysis of HSP67B2 in the (A) gill and (B) hepatopancreas of Macrophthalmus japonicus exposed to 1, 10, and $30 \mu \mathrm{g} \mathrm{L}^{-1}$ DEHP for 1, 4, and 7 days. The values were normalized against GAPDH. Bars indicate the standard deviation of the mean. Statistically significant differences are represented by asterisks as ${ }^{*} P<0.05$ and ${ }^{* *} P<0.01$ as compared to controls (control ratio value $=1$ ).

\section{Discussion}

Cellular responses to stressors are an evolutionary, ubiquitous, and essential mechanism for cell survival. HSPs are known as extrinsic chaperons that are involved in certain cellular processes, such as germ cell differentiation, reproduction, development, thermoprotection, mammalian autoimmune defense, and toxic stress responses, and they have even been regarded as a potential marker of environmental stress [36-42]. HSPs are found in all eukaryotes and are identified based on their size, molecular weight, and functions. HSP60, HSP70 and HSP90 are highly conserved genes and are stress-inducible and multigenic [43]. It has been observed that the HSP60 and HSP70 family members play significant roles in cell survival, stress, and thermal tolerance in response to various heat shocks [44].

Here, we studied two stress-related genes, Mj-HSP60 and Mj-HSP67B2, and conducted expression analysis in different tissues of M. japonicus after treatment with the xenobiotic DEHP. Mj-HSP60 and $M j-H S P 67 B 2$ were highly expressed in the gonad and hepatopancreas, respectively. In addition, these molecules are moderately expressed in the gills, muscle, heart, and stomach. Our findings are consistent with the results of an earlier study showing that the hepatopancreas is the main source of immune 
molecules in crustaceans [45]. The hepatopancreas acts as an essential metabolic center in crustaceans and performs versatile roles in defense systems, detoxification, reactive oxygen species production, digestion, absorption, and nutrient secretion. Owing to the critical importance of the hepatopancreas in detoxification and immunological activities, it is highly sensitive to xenobiotic exposure. Similarly, increased upregulation of HSP90 was noted in the hepatopancreas of P. monodon [46]. In addition, three HSPs, namely MrHSP60, MrHSP70 and MrHSP90, are constitutively expressed in M. rosenbergii during pathogenic infections involving different tissues [47]. Related results were obtained in the Pacific oyster Crassostrea gigas, which exhibits highly upregulated HSP70 expression in the gill tissue after exposure to $\mathrm{Cu}^{2+}$ [48]. DEHP has been shown to alter the expression of HSPs in Chironomus riparius [49,50]. In this species, HSP40 and HSP90 mRNA expression levels increased under various DEHP concentrations for $24 \mathrm{~h}$, which caused morphological deformities [49]. In addition, HSP70 showed increased expression when treated with low doses of DEHP. Overall, our results indicated that two HSPs, Mj-HSP60 and Mj-HSP67B2, in M. japonicus are constitutively expressed, owing to DEHP exposure at day 1 . Hence, these molecules can be considered as upregulated responses of xenobiotic levels for the early exposure time in $M$. japonicus crabs. However, at long-term exposure for 7 days, there are different expression patterns between the Mj-HSP60 and the Mj-HSP67B2 transcripts. The Mj-HSP60 expression was downregulated in most crabs after 7 days of DEHP exposure due to reducing cellular immune protection, although expressions of the detoxifying Mj-HSP67B2 gene [51] were continuously upregulated in DEHP-treated groups compared to the control. HSP67B2 is significant both in detoxification and in anti-oxidative stress systems, as well as immune protection [26,27,51]. For instance, in P. trituberculatus, an important marine and aquaculture species, $M j$-HSP60 displays differential expression patterns in response to environmental salinity stress and exhibits upregulation in the gills [52].

Likewise, L. vannamei HSP60 mRNA is regulated between 4 and $32 \mathrm{~h}$ after the injection of bacteria [53]. HSP70 is upregulated $24 \mathrm{~h}$ after copper exposure in the zebra mussel Dreissena polymorpha and midge larvae Chironomus tentans [54,55]. In addition, HSP70 expression is dramatically induced, owing to microbial pathogens in the Chinese shrimp Fenneropenaeus chinensis [56]. However, little is known regarding the response of HSP60 to xenobiotics and stresses in invertebrates such as the sea anemone (Anemonia viridis) [29], D. polymorpha [54], and the white shrimp (Litopenaeus vannamei) [57]. The limited study reported that HSP67B2 acts like a rhodanese homolog with a single RHOD domain, is characterized from the housefly M. domestica, and plays potential roles under oxidative stress conditions [57]. M. domestica, and plays potential roles under oxidative stress conditions [51]. In crustaceans, HSP expression studies have been conducted on the Asian paddle crab Charybdis japonica, with exposure to EDCs (bisphenol A and 4-nonylphenol) $[16,58]$. To date, this is the first nucleotide and protein sequence information reported regarding Mj-HSP60 and Mj-HSP67B2 in the crab species M. japonicus. Our gene expression results revealed the potential involvement of the two HSPs in the immune system of crabs. This study highlights the potential importance of these molecules in crustaceans, protecting cells against pathogens as well as in severe cellular and environmental stress conditions.

Author Contributions: Conceptualization, K.P., W.-S.K. and I.-S.K; methodology, K.P., W.-S.K. and I.-S.K; formal analysis, K.P., W.-S.K. and I.-S.K; investigation, K.P., W.-S.K. and I.-S.K; resources, K.P., W.-S.K. and I.-S.K; writing — original draft preparation, K.P., W.-S.K. and I.-S.K; supervision, K.P., W.-S.K. and I.-S.K; project administration, I.S.K; funding acquisition, K.P., I.-S.K. All authors have read and agreed to the published version of the manuscript.

Funding: This study was supported by the National Research Foundation of Korea, South Korea, which is funded by the Korean Government [NRF-2018-R1A6A1A-03024314] and [NRF-2019-R1I1A1A-01056855].

Conflicts of Interest: The authors declare that they have no conflicts of interest.

\section{References}

1. Park, K.; Kwak, I.S. Molecular effects of endocrine-disrupting chemicals on the Chironomus riparius estrogen-related receptor gene. Chemosphere 2010, 79, 934-941. [CrossRef] 
2. Lee, Y.S.; Lee, S.; Lim, J.E.; Moon, H.B. Occurrence and emission of phthalates and non-phthalate plasticizers in sludge from wastewater treatment plants in Korea. Sci. Total Environ. 2019, 692, 354-360. [CrossRef]

3. Kim, S.; Lee, Y.S.; Moon, H.B. Occurrence, distribution, and sources of phthalates and non-phthalate plasticizers in sediment from semi-enclosed bays of Korea. Mar. Pollut. Bull. 2020, 151, 110824. [CrossRef] [PubMed]

4. Li, X.; Yin, P.; Zhao, L. Phthalate esters in water and surface sediments of the Pearl River estuary: Distribution, ecological, and human health risks. Environ. Sci. Pollut. Res. 2016, 23, 19341-19349. [CrossRef] [PubMed]

5. Saeed, T.; Al-Jandal, N.; Abusam, A.; Taqi, H.; Al-Khabbaz, A.; Zafar, J. Sources and levels of endocrine disrupting compounds (EDCs) in Kuwait's coastal areas. Mar. Pollut. Bull. 2017, 118, 407-412. [CrossRef] [PubMed]

6. Chen, C.F.; Chen, C.W.; Ju, Y.R.; Dong, C.D. Determination and assessment of phthalate esters content in sediments from Kaohsiung Harbor, Taiwan. Mar. Pollut. Bull. 2017, 124, 767-774. [CrossRef]

7. Paluselli, A.; Fauvelle, V.; Schmidt, N.; Galgani, F.; Net, S.; Sempéré, R. Distribution of phthalates in Marseille Bay (NW Mediterranean Sea). Sci. Total Environ. 2018, 621, 578-587. [CrossRef]

8. Zhang, Z.M.; Zhang, H.H.; Zou, Y.W.; Yang, G.P. Distribution and ecotoxicological state of phthalate esters in the sea-surface microlayer, seawater and sediment of the Bohai Sea and the Yellow Sea. Environ. Pollut. 2018, 240, 235-247. [CrossRef]

9. Park, J.; Park, C.; Gye, M.C.; Lee, Y. Assessment of endocrine-disrupting activities of alternative chemicals for bis (2-ethylhexyl)phthalate. Environ. Res. 2019, 172, 10-17. [CrossRef]

10. Park, K.; Jo, H.; Kim, D.K.; Kwak, I.S. Environmental pollutants impair transcriptional regulation of the vitellogenin gene in the burrowing mud crab (Macrophthalmus japonicus). Appl. Sci. 2019, 9, 1401. [CrossRef]

11. Park, K.; Nikapitiya, C.; Kim, W.S.; Kwak, T.S.; Kwak, I.S. Changes of exoskeleton surface roughness and expression of crucial participation genes for chitin formation and digestion in the mud crab (Macrophthalmus japonicus) following the antifouling biocide irgarol. Ecotoxicol. Environ. Saf. 2016. 132, 186-195. [CrossRef]

12. Kitaura, J.; Nishida, M.; Wada, K. Genetic and behavioral diversity in the Macrophthalmus japonicus species complex (Crustacea: Brachyura: Ocypodidae). Mar. Biol. 2002, 140, 1-8.

13. Park, K.; Kwak, T.S.; Kim, W.S.; Kwak, I.S. Changes in exoskeleton surface roughness and expression of chitinase genes in mud crab Macrophthalmus japonicus following heavy metal differences of estuary. Mar. Pollut. Bull. 2019, 138, 11-18. [CrossRef] [PubMed]

14. Nikapitiya, C.; Kim, W.S.; Park, K.; Kim, J.; Lee, M.O.; Kwak, I.S. Chitinase gene responses and tissue sensitivity in an intertidal mud crab (Macrophthalmus japonicus) following low or high salinity stress. Cell Stress Chaperones. 2015, 20, 517-526. [CrossRef] [PubMed]

15. Nikapitiya, C.; Kim, W.S.; Park, K.; Kwak, I.S. Identification of potential markers and sensitive tissues for low or high salinity stress in an intertidal mud crab (Macrophthalmus japonicus). Fish Shellfish Immunol. 2014, 41, 407-416. [CrossRef] [PubMed]

16. Park, K.; Kwak, I.S. Characterize and gene expression of heat shock protein 90 in marine crab Charybdis japonica following bisphenol A and 4-nonylphenol exposures. Environ. Health Toxicol. 2014, 29, e2014002. [CrossRef]

17. Park, K.; Kim, W.S.; Kwak, I.S. Endocrine-disrupting chemicals impair the innate immune prophenoloxidase system in the intertidal mud crab, Macrophthalmus japonicus. Fish Shellfish Immunol. 2019, 87, 322-332. [CrossRef]

18. Díaz, F.; Orobio, R.F.; Chavarriaga, P.; Toro-Perea, N. Differential expression patterns among heat-shock protein genes and thermal responses in the whitefly Bemisia tabaci (MEAM 1). J. Therm. Biol. 2015, 52, 199-207. [CrossRef]

19. Wu, J.; Liu, T.; Rios, Z.; Mei, Q.; Lin, X.; Cao, S. Heat Shock Proteins and Cancer. Trends Pharmacol. Sci. 2017, 38, 226-256. [CrossRef]

20. Huang, L.H.; Le, K. Cloning and interspecific altered expression of heat shock protein genes in two leafminer species in response to thermal stress. Insect Mol. Biol. 2007, 16, 491-500. [CrossRef]

21. Liu, T.; Daniels, C.K.; Cao, S. Comprehensive review on the HSC70 functions, interactions with related molecules and involvement in clinical diseases and therapeutic potential. Pharmacol. Ther. 2012, 136, 354-374. [CrossRef] [PubMed]

22. Macario, A.J.; Conway de Macario, E. Molecular chaperones: Multiple functions, pathologies, and potential applications. Front. Biosci. 2007, 12, 2588-2600. [CrossRef] [PubMed] 
23. Macario, A.J.; Macario, C.E. Sick chaperones, cellular stress, and disease. N. Engl. J. Med. 2005, 353, $1489-1501$. [CrossRef]

24. Chang, H.C.; Tang, Y.C.; Hayer-Hartl, M.; Hartl, U.C. SnapShot: Molecular chaperones. Part I. Cell 2007, 128, 212. [CrossRef] [PubMed]

25. Tang, Y.C.; Chang, H.C.; Hayer-Hartl, M.; Hartl, U.C. SnapShot: Molecular chaperones. Part II. Cell 2007, 128, 412. [CrossRef]

26. Xu, X.Y.; Shen, Y.B.; Fu, J.J.; Liu, F.; Guo, S.Z.; Yang, X.M.; Li, J.L. Molecular cloning, characterization and expression patterns of HSP60 in the grass carp (Ctenopharyngodon idella). Fish Shellfish Immunol. 2011, 31, 864-870. [CrossRef]

27. Ning, M.X.; Xiu, Y.J.; Bi, J.X.; Liu, Y.H.; Hou, L.B.; Ding, Z.F.; Gu, W.; Wang, W.; Meng, Q.G. Interaction of heat shock protein 60 (HSP60) with microRNA in Chinese mitten crab during Spiroplasma eriocheiris infection. Dis. Aquat. Organ. 2017, 125, 207-215. [CrossRef]

28. Wang, D.; Li, S.; Li, F. Screening of genes regulated by Relish in Chinese shrimp Fenneropenaeus chinensis. Dev. Comp. Immunol. 2013, 41, 209-216. [CrossRef]

29. Livak, K.J.; Schmittgen, T.D. Analysis of relative gene expression data using real time quantitative PCR and the $2^{-\Delta \Delta C T}$ method. Methods 2001, 25, 402-408. [CrossRef]

30. Altschul, S.F.; Gish, W.; Miller, W.; Myers, E.W.; Lipman, D.J. Basic local alignment search tool. J. Mol. Biol. 1990, 215, 403-410. [CrossRef]

31. Bairoch, A.; Bucher, P.; Hofmann, K. The PROSITE database, its status in 1997. Nucleic Acids Res. 1997, 25, 217-221. [CrossRef]

32. Kumar, S.; Stecher, G.; Knyaz, C.; Tamura, K. MEGA X: Molecular evolutionary genetics analysis across computing platforms. Mol. Biol. Evol. 2018, 35, 1547-1549. [CrossRef]

33. Park, K.; Nikapitiya, C.; Kwak, I.S. Identification and expression of proteolysis response genes for Macrophthalmus japonicus exposure to irgarol toxicity. Ann. Limnol. Int. J. Limnol. 2016, 52, 65-74. [CrossRef]

34. Gasteiger, E.; Gattiker, A.; Hoogland, C.; Ivanyi, I.; Appel, R.D.; Bairoch, A. ExPASy: The proteomics server for in-depth protein knowledge and analysis. Nucleic Acids Res. 2003, 31, 3784-3788. [CrossRef] [PubMed]

35. Madeira, F.; Park, Y.M.; Lee, J.; Buso, N.; Gur, T.; Madhusoodanan, N.; Basutkar, P.; Tivey, A.R.N.; Potter, S.C.; Finn, R.D.; et al. The EMBL-EBI search and sequence analysis tools APIs in 2019. Nucleic Acids Res. 2019, 47, W636-W641. [CrossRef] [PubMed]

36. Kozlova, T.; Perezgasga, T.; Reynaud, E.; Zurita, M. The Drosophila melanogaster homologue of the hsp60 gene is encoded by the essential locus 1 (1)10Ac and is differentially expressed during fly development. Dev. Genes Evol. 1997, 207, 253-263. [CrossRef] [PubMed]

37. Meinhardt, A.; Wilhem, B.; Seitz, J. Expression of mitochondrial marker proteins during spermatogenesis. Hum. Reprod. Update 1999, 5, 108-119. [CrossRef]

38. Timakov, B.; Zhang, P. The hsp60B gene in Drosophila melanogaster is essential for the spermatid individualization process. Cell Stress Chaperones 2001, 6, 71-77. [CrossRef]

39. Choresh, O.; Ron, E.; Loya, Y. The 60-kDa heat shock protein (HSP60) of the sea anemone Anemonia viridis: A potential early warning system for monitoring environmental changes. Mar. Biotechnol. 2001, 3, 501-508. [CrossRef]

40. Kammenga, J.E.; Arts, M.S.J.; Oude-Breuil, W.J.M. HSP60 as a potential biomarker of toxic stress in the Nematode Plectus acuminatus. Arch. Environ. Contam. Toxicol. 1998, 34, 253-258. [CrossRef]

41. Chen, Z.; Christina, C.C.H.; Zhang, J.; Cao, L.; Chen, L.; Zhou, L.; Jin, Y.; Ye, H.; Deng, C.; Dai, Z.; et al. Transcriptomic and genomic evolution under constant cold in Antarctic notothenioid fish. Proc. Natl. Acad. Sci. USA 2008, 105, 12944-12949. [CrossRef] [PubMed]

42. Vabulas, R.M.; Ahmad-Nejad, P.; Da Costa, C.; Miethke, T.; Kirschning, C.J.; Haucker, H.; Wagner, H. Endocytosed HSP60s use toll-like receptor 2 (TLR2) and TLR4 to activate the toll/interleukin-1 receptor signaling pathway in innate immune cells. J. Biol. Chem. 2001, 276, 31332-31339. [CrossRef] [PubMed]

43. Lindquist, S.; Craig, E.A. The heat-shock proteins. Annu. Rev. Genet. 1988, 22, 631-677. [CrossRef]

44. Parsell, D.A.; Lindquist, S. The function of heat-shock proteins in stress tolerance: Degradation and reactivation of damaged proteins. Annu. Rev. Genet. 1993, 27, 437-496. [CrossRef] [PubMed]

45. Brunet, M.; Arnaud, J.; Mazz, J. Gut structure and digestive cellular process in marine crustaceans. Oceanogra. Mar. Biol. 1990, 32, 335-367. 
46. Rungrassamee, W.; Leelatanawit, R.; Jiravanichpaisal, P.; Klinbunga, S.; Karoonuthaisiri, N. Expression and distribution of three heat shock protein genes under heat shock stress and under exposure to Vibrio harveyi in Penaeus monodon. Dev. Comp. Immunol. 2010, 34, 1082-1089. [CrossRef]

47. Chaurasia, M.K.; Nizam, F.; Ravichandran, G.; Arasu, M.V.; Al-Dhabi, N.A.; Arshad, A.; Elumalai, P.; Arockiaraj, J. Molecular importance of prawn large heat shock proteins 60, 70 and 90. 2016. Fish Shellfish Immunol. 2016, 48, 228-238. [CrossRef]

48. Luan, W.; Li, F.; Zhang, J.; Wen, R.; Li, Y.; Xiang, J. Identification of a novel inducible cytosolic Hsp70 gene in Chinese shrimp Fenneropenaeus chinensis and comparison of its expression with the cognate Hsc70 under different stresses. Cell Stress Chaperones 2010, 15, 83-93. [CrossRef]

49. Park, K.; Kwak, I.S. Characterization of heat shock protein 40 and 90 in Chironomus riparius larvae: Effects of di (2-ethylhexyl) phthalate exposure on gene expressions and mouthpart deformities. Chemosphere 2008, 74, 89-95. [CrossRef]

50. Morales, M.; Planelló, R.; Martínez-Paz, P.; Herrero, O.; Cortés, E.; Martínez-Guitarte, J.L.; Morcillo, G. Characterization of Hsp70 gene in Chironomus riparius: Expression in response to endocrine disrupting pollutants as a marker of ecotoxicological stress. Comp. Biochem. Physiol. C Toxicol. Pharmacol. 2011, 153, 150-158. [CrossRef]

51. Tang, T.; Sun, H.; Li, Y.; Chen, P.; Liu, F. MdRDH1, a HSP67B2-like rhodanese homologue plays a positive role in maintaining redox balance in Musca domestica. Mol. Immunol. 2019, 107, 115-122. [CrossRef]

52. Xu, Q.; Qin, Y. Molecular cloning of heat shock protein 60 (PtHSP60) from Portunus trituberculatus and its expression response to salinity stress. Cell Stress Chaperones 2012, 17, 589-601. [CrossRef] [PubMed]

53. Qian, D.; Shi, Z.; Zhang, S.; Cao, Z.; Liu, W.; Li, L. Extra small virus-like particles (XSV) and nodavirus associated with whitish muscle disease in the giant freshwater prawn, Macrobrachium rosenbergii. J. Fish Dis. 2003, 26, 521-527. [CrossRef] [PubMed]

54. Clayton, M.E.; Steinmann, R.; Fent, K. Different expression patterns of heat shock proteins hsp 60 and hsp 70 in zebra mussels (Dreissena polymorpha) exposed to copper and tributyltin. Aquat. Toxicol. 2000, 47, 213-226. [CrossRef]

55. Karouna-Renier, N.K.; Zehr, J.P. Short-term exposures to chronically toxic copperconcentrations induce HSP70 proteins in midge larvae (Chironomus tentans). Sci. Total Environ. 2003, 312, 267-272. [CrossRef]

56. Li, F.H.; Luan, W.; Zhang, C.S.; Zhang, J.Q.; Wang, B.; Xie, Y.S. Cloning of cytoplasmic heat shock protein 90 (FcHSP90) from Fenneropenaeus chinensis and its expression response to heat shock and hypoxia. Cell Stress Chaperones 2009, 14, 161-172. [CrossRef]

57. Zhou, J.; Wang, W.N.; He, W.Y.; Zheng, Y.; Wang, L.; Xin, Y.; Liu, Y.; Wang, A.L. Expression of HSP60 and HSP70 in white shrimp, Litopenaeus vannamei in response to bacterial challenge. J. Invertebr. Pathol. 2010, 103, 170-178. [CrossRef]

58. Park, K.; Kwak, I.S. Expression of stress response HSP70 gene in Asian paddle crabs, Charybdis japonica, exposure to endocrine disrupting chemicals, bisphenol A (BPA) and 4-nonylphenol (NP). Ocean Sci. J. 2013, 48, 207-214. [CrossRef]

(C) 2020 by the authors. Licensee MDPI, Basel, Switzerland. This article is an open access article distributed under the terms and conditions of the Creative Commons Attribution (CC BY) license (http://creativecommons.org/licenses/by/4.0/). 